\title{
The interplay between social dominance orientation and intergroup contact in explaining support for multiculturalism
}

\author{
Emilio Paolo Visintin ${ }^{1,2}$ (D) | Jacques Berent ${ }^{2,3}$ (D) | Eva G. T. Green ${ }^{2}$ (D) | \\ Juan Manuel Falomir-Pichastor ${ }^{3}$
}

\author{
${ }^{1}$ Department of Humanities, University of \\ Ferrara, Ferrara, Italy \\ ${ }^{2}$ Institute of Psychology, University of \\ Lausanne, Lausanne, Switzerland \\ ${ }^{3}$ Faculty of Psychology and Educational \\ Sciences, University of Geneva, Geneva, \\ Switzerland \\ Correspondence \\ Emilio Paolo Visintin, Department of \\ Humanities, University of Ferrara, via \\ Paradiso 12, Ferrara 44121, Italy. \\ Email: emiliop.visintin@gmail.com \\ Funding information \\ Swiss National Science Foundation, Grant/ \\ Award Number: 100014_159336 and \\ 51NF40-142020
}

\begin{abstract}
In two studies, we tested whether social dominance orientation (SDO) and intergroup contact interacted in shaping support for multiculturalism. Study 1 was correlational, while in Study 2 we measured SDO and experimentally manipulated intergroup contact (imagined contact paradigm). We found that SDO and intergroup contact interacted on support for multiculturalism: Intergroup contact was associated with more support for multiculturalism only for high-SDO individuals, and SDO was negatively associated to support for multiculturalism more strongly for individuals with low or no contact. Finally, we discussed the role of the intergroup setting in which studies are conducted.
\end{abstract}

\section{1 | INTRODUCTION}

In contemporary societies, rights of ethnic and immigrant minorities are often questioned by national majorities. Indeed, majorities may strive to preserve their advantages, and frequently prefer that minorities prioritize local customs, language, and culture over their culture of origin (e.g., Verkuyten, 2006). In this research, we analyze factors underlying majorities' support of multiculturalism, operationalized as support for a culturally diverse society where minority groups are allowed and encouraged to preserve their culture, and where civic, social, and political rights are equal between citizens and immigrants (see Breugelmans \& van de Vijver, 2004; Green \& Staerklé, 2013; Verkuyten, 2006). Specifically, we examine whether social dominance orientation (SDO, Sidanius \& Pratto, 1999)-an ideology which legitimizes group-based hierarchies and inequalities-and intergroup contact with immigrants (Pettigrew \& Tropp, 2006) jointly impact support for multiculturalism in Switzerland. With two studies, we extend previous research in three ways. First, we focus on support for multiculturalism, instead of intergroup attitudes, as past research has mostly done. This is crucial because societies implementing multicultural policies strive for equal rights between nationals and immigrants, whereas high-SDO individuals generally reject intergroup equality. Second, we examine the interplay between SDO and intergroup contact in a specific, underexplored intergroup context, Switzerland, where immigrants do not univocally have lower status compared to Swiss nationals, but part of the immigrant population has high status and thus can represent a challenge to the societal hierarchy. Third, we test the predicted effects both by measuring and experimentally manipulating intergroup contact.

\section{2 | SDO, INTERGROUP CONTACT, AND THEIR INTERPLAY}


Intergroup contact (i.e., encounters between members of different groups), in turn, is considered one of the most important factors contributing to prejudice reduction (Allport, 1954; Pettigrew \& Tropp, 2006) by disconfirming negative stereotypes and reducing threat perceptions and intergroup anxiety, as well as by increasing positive emotional reactions toward the out-group (Pettigrew \& Tropp, 2008). Crucial for the present research, intergroup contact has been found to be positively associated to support for multiculturalism (e.g., Verkuyten, Thijs, \& Bekhuis, 2010).

Whereas a lot of research has investigated the independent impact of SDO and intergroup contact on intergroup attitudes, the few studies examining the interactive effects of SDO and intergroup contact have yielded mixed findings. On the one hand, some researchers have proposed that intergroup contact might be particularly effective in reducing prejudice among people who are predisposed to prejudice (i.e., with high levels of SDO). Indeed, intergroup contact has the potential to attenuate antecedents of prejudice, many of which are possessed by high-SDO individuals, such as lack of empathy (Hodson, 2008). Also, high-SDO people usually avoid intergroup contacts. However, when positive contacts between high-SDO people and out-group members occur, these contacts are likely to be momentous experiences, which challenge beliefs and stereotypes and have thus high potential to improve intergroup attitudes. In line with these arguments, Hodson (2008) conducted two studies in British prisons and found that White inmates' contact experiences with Black inmates were especially effective at reducing intergroup bias among White inmates high on SDO. Similarly, Dhont and Van Hiel (2009) showed that Flemish adults' positive contacts with immigrants were associated with reduced racism among those with high SDO.

On the other hand, the opposite pattern of results has been predicted and revealed, that is, the beneficial effects of contact on prejudice reduction are lower for individuals with high SDO. The underlying reasoning is that high-SDO individuals are motivated by the desire to promote and maintain intergroup hierarchies, even when experiencing intergroup contact (Asbrock, Christ, Duckitt, \& Sibley, 2012). This claim echoes the initial proposition by Allport (1954) that some personality characteristics highly associated to prejudice might prevent benefitting from contact. For example, Schmid, Hewstone, Küpper, Zick, and Wagner (2012) analyzed contact experiences with and prejudice toward immigrants among general population samples in eight European countries. The overall results pattern suggested stronger associations between intergroup contact and prejudice reduction for people low (vs. high) on SDO. Similar findings were reported in the context of Germans' relations to immigrant and ethnic minorities (Asbrock et al., 2012, Study 1; see also Asbrock, Gutenbrunner, \& Wagner, 2013, Study 1).

Finally, Kteily, Hodson, Dhont, and Ho (2019) found no consistent moderation patterns when analyzing White Americans' contact quality with Blacks, SDO, and several prejudice indicators: Contact quality was generally associated with reduced prejudice, irrespective of SDO levels (see also Asbrock et al., 2012, Study 2). Given inconsistencies in previous findings, more research is needed. Here, we examine the interplay between SDO and intergroup contact in the intergroup context of Swiss nationals and immigrants in Switzerland.

\section{3 | OVERVIEW OF THE STUDIES}

In two studies, we test whether SDO and intergroup contact interact in predicting support for multiculturalism among the Swiss majority. By focusing on multiculturalism, we go beyond previous research on the interplay between SDO and contact which focused on prejudice and intergroup attitudes. Positive intergroup attitudes do not necessarily entail support for concrete multicultural policies (e.g., see principle-implementation gap; Dixon, Durrheim, \& Tredoux, 2007). Support for multiculturalism instead implies acceptance of policies that provide immigrants with equal rights and allow nurturing heritage cultures. As intergroup equality is a goal for societies implementing multicultural policies, high-SDO people are likely to reject such an organization of society (Pratto et al., 2006). It is thus crucial to know whether intergroup contact can curb such rejection, and if intergroup contact relates to increased support for multiculturalism even among high-SDO people.

Switzerland-the context of the current research-is a wealthy country with a high proportion of immigrants (24.6\%; Swiss Federal Statistical Office [SFSO], 2017). When considering the overall immigrant population, compared to Swiss nationals, immigrants have higher unemployment rates, lower salaries, and higher risk of being employed as overqualified (SFSO, 2017). Yet the immigrant population is heterogeneous regarding educational levels, occupations, and status of immigrants. Indeed, numerous research centers, pharmaceutical industries, NGOs, and multinational corporations rely on highly educated and qualified foreign employees in Switzerland, because there are not enough Swiss citizens with tertiary education to fulfill the human capital needs of such organizations. Though on average immigrant population has a lower status than the Swiss majority, it can be seen as challenging the societal hierarchy where the national ingroup has a higher status compared to immigrant minorities. Moreover, the prominent campaigning of the radical right (Swiss People's Party) frequently underscores these challenges. In such a context, SDO should also be a particularly relevant predictor of rejection of multiculturalism, as rejection of multiculturalism allows preserving the higher status of the Swiss national majority. In this vein, in an analysis across 20 countries, Pratto et al. (2013) found that the negative association between SDO and support for protection of ethnic and religious minorities was the strongest in Switzerland. Furthermore, assimilationism is the predominant cultural diversity ideology in Switzerland (Guimond, de la Sablonnière, \& Nugier, 2014): Swiss nationals generally prefer immigrants to assimilate to Swiss customs, culture, and languages and do not support multiculturalism. Yet, given the high proportion of immigrants in Switzerland, opportunities for daily contacts and friendships between nationals and immigrants are abundant. Switzerland is thus a fascinating context for examining how SDO and intergroup contact jointly shape support for multiculturalism. 
The two studies were conducted in two different Swiss linguistic regions: Study 1 was conducted in the Italian speaking region (Ticino canton), while Study 2 was run in the French speaking region (Vaud canton). Both Ticino and Vaud have high proportions of immigrants, especially of immigrants coming from Southern European countries (Italians in Ticino and Portuguese in Vaud, SNSF, 2017). Both areas are also characterized by high proportions of frontier workers, that is, people living in the neighboring countries (France and Italy, respectively) and commuting daily to Switzerland to work. Attitudes toward ethnic minorities and immigration are however more tolerant in the Frenchspeaking cantons than in Ticino (e.g., Mazzoleni \& Pilotti, 2015).

Based on previous research, alternative predictions can be drawn regarding the direction of the interplay between SDO and contact on multiculturalism. In line with Hodson (2008) and Dhont and Van Hiel (2009), the association between intergroup contact and multiculturalism support should be stronger for high-SDO individuals, as compared to low-SDO individuals. Alternatively, in line with Schmid et al. (2012) and with Asbrock et al. (2012, Study 1; 2013, Study 1), the effects of intergroup contact should be stronger among low-SDO than among high-SDO individuals.

In addition, we examine this phenomenon from another angle: While previous research has usually treated intergroup contact as the predictor and SDO as the moderator, we also test whether the effects of SDO on support for multiculturalism vary as a function of intergroup contact. Indeed, according to social dominance theory, SDO and its associations with other variables are shaped by context and personal experiences (Pratto et al., 2006) such as contacts with out-group members. As contact has powerful effects on prejudice reduction (e.g., Pettigrew \& Tropp, 2006), we expect that it curbs the negative association between SDO and support for multiculturalism.

\section{4 | STUDY 1}

Study 1 is a correlational study where SDO, intergroup contact, and support for multiculturalism were all measured.

\section{1 | Participants and procedure}

Both studies were conducted in line with the ethical guidelines of the American Psychological Association and of the Swiss Psychological Society. Ninety-two students from a high school in Ticino filled out a questionnaire during classes. Data analyses were conducted on the 89 respondents with a Swiss nationality $(54 \%$ of females; $M_{\text {age }}=17.87, S D_{\text {age }}=0.83 ; 31$ had dual nationality, i.e., they had Swiss nationality and another nationality). Cronbach's alphas, means, standard deviations, and correlations between variables are reported in Table 1.

\subsection{1 | SDO}

To keep the questionnaire short, we selected four statements from the 16-item SDO6 scale (Sidanius \& Pratto, 1999; e.g., "Inferior groups should stay in their place") and translated them in Italian. Respondents rated their agreement on a scale ranging from 1 (strongly disagree) to 5 (strongly agree). Two items were reverse coded. Responses were averaged to create a composite score with higher values representing higher levels of SDO.

\subsection{2 | Intergroup contact}

Respondents answered four questions investigating the frequency of their contacts with immigrants (e.g., "How frequently do you have contacts with immigrants at school?"; 1 = never; 5 = very often; adapted from Islam \& Hewstone, 1993). A composite score was created by averaging answers to the items, with higher scores reflecting more intergroup contact.

\subsection{3 | Support for multiculturalism}

Respondents rated their agreement with 13 items on a scale ranging from 1 (I do not agree at all) to 7 (I fully agree). The statements (based on Frederic \& Falomir-Pichastor, 2018, Study 3 and on Levin et al., 2012) were about whether Switzerland should support cultural maintenance and whether Swiss citizens and immigrants should have the same civic, social, and political rights (e.g., "Switzerland should help immigrants preserve their cultural heritage" and "Immigrants should have the same rights than Swiss citizens"). Five items were reverse coded. A principal component analysis (PCA) revealed that all the items loaded on one factor (factor loadings above 0.39) explaining $44 \%$ of variance. We thus created a composite score with higher scores representing more support for multiculturalism.

\section{2 | Results and discussion}

The hypothesis was tested with a regression analysis with support for multiculturalism as the dependent variable. SDO, intergroup

TAB LE 1 Cronbach's alphas, means, standard deviations, and correlations between variables (Study 1)

\begin{tabular}{llll} 
& Cronbach's alpha & M(SD) & 1 \\
1. Intergroup contact & 0.88 & $2.79(1.01)$ & - \\
2. SDO & 0.81 & $1.85(0.78)$ & $-0.22^{*}$ \\
3. Support for multiculturalism & 0.89 & $4.87(1.10)$ & $0.25^{*}$ \\
\hline
\end{tabular}

Note. Intergroup contact and SDO scores range from 1 to 5 . Support for multiculturalism scores range from 1 to 7. $p<0.05 .{ }^{* * *} p \leq 0.001$. 
TAB LE 2 Regression analyses of the effects of intergroup contact, SDO, and their interaction on support for multiculturalism

\begin{tabular}{|c|c|c|c|c|}
\hline & \multicolumn{2}{|l|}{ Study 1} & \multicolumn{2}{|l|}{ Study 2} \\
\hline Intercept & $4.87(0.09)^{* * *}[4.69,5.05]$ & $4.92(0.09)^{* * *}[4.74,5.10]$ & $4.87(0.10)^{* * *}[4.66,5.08]$ & $4.85(0.10)^{* * *}[4.64,5.05]$ \\
\hline $\begin{array}{l}\text { Intergroup } \\
\text { contact }\end{array}$ & $0.13(0.09)[-0.06,0.31]$ & $0.15(0.09)[-0.03,0.34]$ & $0.07(0.11)[-0.14,0.28]$ & $0.07(0.10)[-0.14,0.28]$ \\
\hline SDO & $-0.85(0.12)^{* * *}[-1.09,-0.61]$ & $-0.78(0.12)^{* * *}[-1.02,-0.54]$ & $-0.83(0.16)^{* * *}[-1.14,-0.52]$ & $-0.81(0.15)^{* * *}[-1.11,-0.50]$ \\
\hline F-value & $29.90^{* * *}$ & $22.27^{* * *}$ & $14.26^{* * *}$ & $11.16^{* * *}$ \\
\hline$d f$ & 2,86 & 3,85 & 2,73 & 3,72 \\
\hline$R^{2}$ & 0.41 & 0.44 & 0.28 & 0.32 \\
\hline
\end{tabular}

Note. Unstandardized B coefficients, (standard errors), and [95\% confidence intervals] are reported. Intergroup contact was measured in Study 1 and experimentally manipulated (imagined contact paradigm) in Study 2.

${ }^{\circ} p=0.054 .^{*} p<0.05 .^{* * *} p \leq 0.001$.

contact, and their product were treated as predictors. SDO and intergroup contact scores were centered (Aiken, West, \& Reno, 1991).

As predicted, the SDO $\times$ intergroup contact interaction yielded a significant effect on support for multiculturalism (see Table 2 for results of the regression analysis). Decomposition of the interaction showed that intergroup contact was positively associated to multiculturalism support for respondents with high SDO (+1 SD), $B=0.34, S E=0.13, p=0.013,95 \% \mathrm{Cl}=[0.07,0.61]$ but not for respondents with low SDO $(-1 S D), B=-0.03, S E=0.12, p=0.77$, $95 \% \mathrm{Cl}=[-0.27,0.20]$. Moreover, the negative association between SDO and multiculturalism support was stronger for respondents with low intergroup contact ( $-1 S D), B=-1.03, S E=0.14, p<$ $0.001,95 \% \mathrm{Cl}=[-1.31,-0.74]$, than for respondents with high contact with immigrants $(+1 S D), B=-0.54, S E=0.19, p=0.006$, 95\% $\mathrm{Cl}=[-0.91,-0.16]$ (Figure 1$){ }^{1}$

Taken together, results of Study 1 suggest that SDO and personal experiences of intergroup contact interact in shaping support for multiculturalism. Specifically, intergroup contact appears to be beneficial for supporting multiculturalism among people who strongly endorse group hierarchies. Furthermore, the detrimental effects of endorsing group hierarchies on supporting multiculturalism are reduced for those with frequent contacts with immigrants.

\section{5 | STUDY 2}

Study 2 aims at replicating and extending results of Study 1 . Because Study 1 was correlational, causal conclusions could not be drawn. Thus, in Study 2, we experimentally manipulated intergroup contact with the imagined contact paradigm (Crisp \& Turner, 2012). Turner, Crisp, and

\footnotetext{
${ }^{1}$ Because individuals with dual nationality have a mixed national, and sometimes also ethnic, background, they may support multiculturalism more than individuals who are exclusively Swiss citizens (see e.g., Sarrasin, Green, Bolzman, Visintin, \& Politi, 2018). In an additional analysis, we controlled for Swiss only (coded -1 ) versus dual (coded +1 ) nationality Possessing dual nationality was however not associated to support more for multiculturalism, $p=0.456$. The results pattern was identical in essence to the above-reported one.
}

Lambert (2007) proposed and demonstrated that the mere imagination of a positive encounter with a member of the out-group (i.e., an imagined intergroup contact) has the potential to reduce prejudice (for a meta-analysis, see Miles \& Crisp, 2014). Importantly, imagined contact has been found to be particularly effective in prejudice reduction among people with initial negative out-group attitudes (West, Hotchin, $\&$ Wood, 2017). Given that high-SDO individuals are generally those with high prejudice levels, and building on findings of Study 1 , we expect imagined contact to buffer the association between SDO and reduced multiculturalism support, and to be particularly effective among high-SDO individuals.

\section{1 | Participants and procedure}

Eighty-nine respondents were recruited in public areas of a university campus in the French-speaking part of Switzerland. However, we excluded from data analysis non-Swiss respondents $(n=4)$, and non-students $(n=9)$ to have a homogenous sample. The final sample consisted of 76 Swiss university students (54\% of females; $M_{\text {age }}=22.75, S D_{\text {age }}=3.68 ; 32$ had dual nationality).

Respondents received a questionnaire including first the SDO measure, next the imagined intergroup contact versus control experimental manipulation, and finally the support for multiculturalism measure. Cronbach's alphas, means, and standard deviations by experimental condition, and correlation between variables are reported in Table 3.

\subsection{1 | SDO}

While in Study 1 we selected four items from the full SDO6 scale, in Study 1 we used the Short SDO scale (SSDO, Pratto et al., 2013) which is a 4-item SDO scale validated by Pratto and colleagues across 20 countries, including Switzerland. Respondents rated their agreement with four statements ( 1 = strongly disagree; 5 = strongly agree e.g., "Superior groups should dominate inferior groups"). Two items were reverse coded before creating a composite score by averaging the answers. Higher scores indicate higher levels of SDO. 


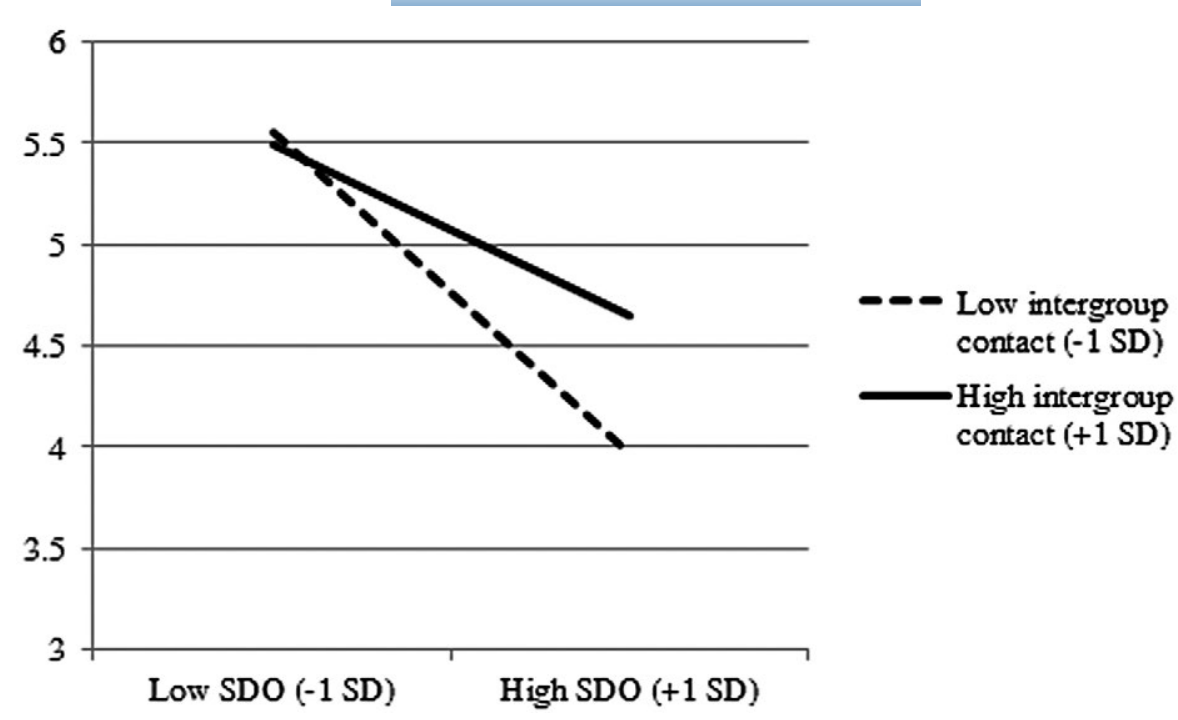

FIGURE 1 The association between SDO and support for multiculturalism as a function of intergroup contact (Study 1)

TA B LE 3 Cronbach's alphas, means and standard deviations by experimental condition, and correlations between variables (Study 2)

\begin{tabular}{|c|c|c|c|c|c|c|}
\hline & & $\begin{array}{l}\text { Imagined contact } \\
\text { condition }\end{array}$ & Control condition & & & \\
\hline & Cronbach's alpha & $M(S D)$ & $M(S D)$ & $t$-test & $p$-value of $t$-test & $r$ \\
\hline 1. SDO & 0.65 & $1.97(0.69)$ & $1.84(0.67)$ & 0.85 & 0.40 & - \\
\hline $\begin{array}{l}\text { 2. Support for } \\
\text { multiculturalism }\end{array}$ & 0.90 & $4.88(1.12)$ & $4.84(1.02)$ & 0.14 & 0.89 & $-0.53^{* * *}$ \\
\hline
\end{tabular}

Note. SDO scores range from 1 to 5 . Support for multiculturalism scores range from 1 to 7 . ${ }^{* * *} p<0.001$.

\subsection{2 | Imagined intergroup contact experimental manipulation}

Participants were randomly assigned to the imagined contact $(n=34)$ or to the control $(n=42)$ condition. Respondents in the imagined contact condition were invited to imagine an encounter on the bus with an unknown immigrant (see Turner et al., 2007). The instructions stressed that, during the encounter, the respondent would have discovered interesting, unexpected, and positive things about the conversation partner. Respondents in the control condition were asked to imagine an outdoors scene (see Appendix). In both conditions, respondents were asked to write down what they imagined, as a reinforcement of the manipulations. ${ }^{2}$

\subsection{3 | Support for multiculturalism}

Support for multiculturalism was assessed with the same measure as in Study 1. Similarly to Study 1, a PCA showed that all the items

\footnotetext{
${ }^{2}$ Preliminary analyses revealed that respondents in the imagined contact versus contro condition did not differ by proportion of dual nationals, $\chi^{2}(1)=1.17, p=0.279$, and SDO, $t(74)=0.85, p=0.397$. They instead differed by age, $t(71)=2.17, p=0.033$, with respondents in the imagined contact condition older $(M=23.71, S D=2.69)$ than respondents in the control condition $(M=21.98, S D=4.20)$, and by gender, $\chi^{2}(1)=4.04, p=0.044$, with a higher female ratio among respondents in the control condition (64\%) than among respondents in the imagined contact condition (41\%). When running the regression analysis controlling for gender and for age, the main results did not change. Gender was not associated to support for multiculturalism, $p=0.817$, while older respondents reported more support for multiculturalism, $B=0.07, S E=0.03, p=0.029,95 \% \mathrm{Cl}=[0.01,0.13]$.
}

loaded on one factor (factor loadings above 0.45 ) explaining $45 \%$ of variance.

\section{2 | Results and discussion}

To test our hypothesis, we proceeded with a regression analysis in which support for multiculturalism was used as the dependent variable. SDO (centered), imagined intergroup contact ( -1 = control; +1 = imagined intergroup contact), and their product were used as predictors. The effect of the SDO $\times$ imagined contact interaction was marginally significant ( $p=0.054$; Table 2). Planned comparisons were performed (see Rosenthal \& Rosnow, 1985). These analyses revealed that imagined contact (vs. control) marginally increased support for multiculturalism among respondents with relatively high levels of SDO (+1 SD), $B=0.27$, $S E=0.14, p=0.065,95 \% \mathrm{Cl}=[-0.02,0.56]$, while it had no effect for respondents with low SDO (-1 SD), $B=-0.14, \mathrm{SE}=0.15, p=0.365,95 \%$ $\mathrm{Cl}=[-0.43,0.16]$. Moreover, the negative association between SDO and support for multiculturalism was stronger for respondents in the control condition, $B=-1.11, S E=0.21, p<0.001,95 \% \mathrm{Cl}=[-1.52$, -0.69], than for respondents in the imagined contact condition, $B=$ $-0.51, S E=0.22, p=0.027,95 \% \mathrm{Cl}=[-0.96,-0.06]$ (Figure 2). ${ }^{3}$

\footnotetext{
${ }^{3}$ Also in Study 2, we further controlled for Swiss only $(-1)$ versus dual $(+1)$ nationality. Dua nationality was associated with more support for multiculturalism, $B=0.22, S E=0.10, p=$ $0.04,95 \% \mathrm{Cl}=[0.01,0.42]$. The results pattern was identical in essence to the one reported above.
} 


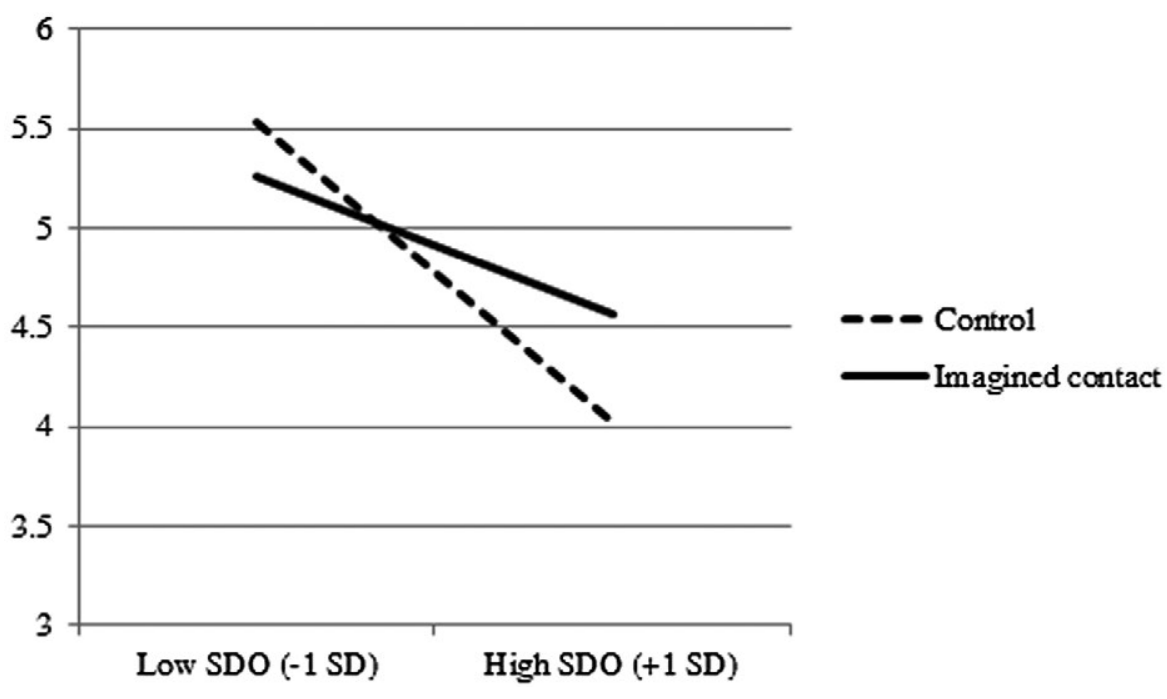

FIGURE 2 The association between SDO and support for multiculturalism as a function of imagined intergroup contact versus control (Study 2)
Results of Study 2 replicate those of Study 1 using an experimental manipulation of intergroup contact. Specifically, imagining an intergroup encounter appears to be beneficial in terms of increasing support for multiculturalism, but only for people high in SDO. Also, the negative association between SDO and support for multiculturalism is reduced for respondents who have imagined an encounter with an immigrant (as compared to respondents invited to imagine an outdoors scene).

\section{6 | GENERAL DISCUSSION}

Across two studies, we analyzed correlates of support for multiculturalism, operationalized as support for a culturally diverse society where minority groups are allowed and encouraged to preserve their culture, and where majorities and minorities have equal rights. We found that encounters with immigrants (i.e., intergroup contact) and preference for group-based hierarchies (SDO) interacted in predicting multiculturalism support. Specifically, intergroup contact was associated with more multiculturalism support only among respondents high in SDO. Moreover, the detrimental effect of SDO on multiculturalism support was reduced among respondents having frequent contacts with immigrants (Study 1), and among those imagining a positive encounter with an unknown immigrant (Study 2 ). ${ }^{4}$

Our research contributes to the literature on the interplay between ideological attitudes and intergroup contact in several ways. First, our results point to the efficacy of intergroup contact among individuals with anti-egalitarian, hierarchical, and dominant views of intergroup relations, converging with findings by Hodson (2008) and by Dhont

\footnotetext{
${ }^{4}$ While the current research focuses on the SDO $\times$ contact interaction, a mediation is also conceivable. In line with Dhont Van Hiel and Hewstone (2014), intergroup contact might be associated with reduced SDO, and SDO might thus mediate the association between intergroup contact and multiculturalism support. This hypothesized mediation mode could only be tested with Study 1 data, because in Study 2 SDO was measured before the imagined contact versus control experimental manipulation. Indeed, in Study 1 we found a significant indirect effect of intergroup contact on multiculturalism support via SDO, $B=0.15, S E_{(\text {boot })}=0.08,95 \% \mathrm{Cl}=[0.02,0.35]$. Yet given that in Study 2, SDO was measured before manipulating intergroup contact, and that we found an interaction between SDO and intergroup contact, we are confident that a moderation exists.
}

and Van Hiel (2009). Second, our findings are also in line with the conceptualization of SDO as a variable whose strength and effects are shaped by personal experiences and contextual factors (see Pratto et al., 2006). Specifically, intergroup contact appears to shape the effects of SDO on multiculturalism support, by reducing its detrimental effects. Our results thus provide further evidence in favor of intergroup contact theory (Pettigrew \& Tropp, 2006), by showing that intergroup contact is not only a powerful buffer against prejudice, but it can also curb the effects of strong antecedents of prejudice such as SDO.

Study 2 also shed light on the boundary conditions of the effectiveness of imagined intergroup contact. Indeed, some replication failures of the imagined contact effect have questioned the validity of the paradigm (e.g., Dermody, Jones, \& Cumming, 2013; Klein et al., 2014), and led to suggestions that imagined contact might be effective only in some circumstances. In Study 2, we did not find a main effect of imagined contact (see Tables 2 and 3), implying that imagined contact was not, per se, sufficient for increasing people's support for multiculturalism. However, imagined contact was effective among high-SDO respondents. While previous research has shown that imagined contact can be particularly beneficial in terms of prejudice reduction for people with initial prejudice (West et al., 2017), we show for the first time that it can be particularly beneficial also for those with anti-egalitarian ideological orientations.

That said, it is worth reflecting whether the results pattern is specific to the context under study. On the one hand, Switzerland is characterized by high opportunities for contacts with immigrants, on the other hand, in Switzerland SDO is particularly detrimental for attitudes toward immigrants (Pratto et al., 2013), who might be perceived as challenging hierarchies in Swiss society. We speculate that our results pattern might occur in contexts characterized by pronounced groupbased hierarchies and high contact opportunities. For example, research by Hodson (2008) which yielded similar results was conducted in prisons, an environment characterized by hierarchy but also by frequent contacts between inmates with different origins. Also, as Dhont and Van Hiel (2009) findings in Belgium were similar to ours, this results pattern might characterize relationships between nationals and immigrants in countries where there are relatively high proportions of 
highly skilled immigrants (see Bosetti, Cattaneo, \& Verdolini, 2015). Indeed, high-skilled immigrants might pose a challenge to group hierarchies, but nationals are also likely to have contacts with high-skilled immigrants and such contacts might reduce the effects of SDO. The same pattern was found across two linguistic regions, that is, the Italian-speaking and the French-speaking areas of Switzerland, which are quite similar in terms of immigrant ratios and presence of frontier workers, though historically attitudes toward immigration are more tolerant in the French-speaking than in the Italian-speaking area.

Even though our results are consistent and insightful, we must acknowledge some limitations of our studies that pave the way to future research. First, though we experimentally manipulated intergroup contact in Study 2, in both studies SDO was measured. Hence, causality could not be fully established. Future research would do well in using longitudinal designs, or full experiments where all predictors are experimentally manipulated. Second, we acknowledge a limitation in the assessment of SDO: In Study 1, we selected only four items from the 16-item SDO6 scale, instead of using the full SDO6 scale, to keep the questionnaire short. This limitation was overcome in Study 2, where we used a short SDO scale which was previously validated in Switzerland (among other countries; Pratto et al., 2013). For a more comprehensive assessment of SDO, future research would however do well in using the full SDO6 scale. Third, we controlled for dual nationality (see Footnotes 1 and 3), but did not measure other characteristics such as participants' ethnicity and religious belonging which might impact multiculturalism support and should thus be controlled for in future research.

Fourth, as usual with student samples, our respondents exhibited support for multiculturalism and low-SDO levels. The examination of student samples might underlie the non-significant main effect of intergroup contact on multiculturalism support in both studies (Table 2): Given that multiculturalism is relatively high, intergroup contact might not be necessary for fostering it. Examination of student samples might also explain finding similar effects across two linguistic regions, which differ in attitudes about immigration. To ensure that choice of sample did not dilute regional differences, future research should analyze representative samples of non-student populations.

Other fruitful avenues for further research should also be put forward. It would be relevant to distinguish immigrants from different origins and status. Contact is easier to establish with culturally close immigrants (such as French or Italians in Switzerland; see Green, Fasel, \& Sarrasin, 2010) than with culturally distant immigrants. Further, high-SDO individuals are more likely than low-SDO individuals to put different ethnic groups in hierarchy, favoring culturally close immigrants over culturally distant immigrants (Snellman \& Ekehammar, 2005). However, culturally close immigrants are also likely to be those perceived as possessing higher status and challenging group hierarchies (see e.g., Jetten \& Spears, 2003), and might thus elicit resistance against equal rights among high-SDO individuals. To account for this complexity and heterogeneity of the immigrant population, future research should analyze whether the interplay between SDO and contact with immigrants has different effects as a function of origins and status of immigrants.

Moreover, the mechanisms underlying the interplay between SDO and intergroup contact on multiculturalism support need spelling out. It might be that perceived out-group competitiveness is a particularly good explanation of the effects we observed (see Duckitt \& Sibley, 2009). Indeed, people high in SDO might perceive immigrants as competing and challenging the status quo, and reject multiculturalism to preserve the status quo. However, intergroup contact should curb these associations. Also, the representation of multiculturalism and cultural diversity might underlie our findings. High-SDO individuals who have contacts with immigrants might shift their perception of multiculturalism and diversity seeing it beneficial for the society and no longer threatening (see e.g., Mahfud, Badea, Guimond, Anier, \& Ernst-Vintila, 2016). Finally, in line with Hodson (2008), empathy toward out-group members might as well contribute to explain the observed effects.

The current research revealed joint effects of SDO and intergroup contact on support for multiculturalism. In conclusion, these findings suggest that in demographically diverse societies where the existing group-based hierarchy is potentially challenged, or at least the populist right suggests so, fostering intergroup contact can heighten endorsement of multicultural policies among people with anti-egalitarian views.

\section{ACKNOWLEDGMENTS}

This work was supported by the Swiss National Science Foundation (Division 1 grant no. 100014_159336; National Center of Competence in Research (NCCR)-on the move grant no. 51NF40-142020; both grants were awarded to Eva G. T. Green and Juan Manuel Falomir-Pichastor). The authors would like to thank Sceryl Ulleri and Michael Rubattel for their assistance with data collection and coding.

\section{ORCID}

Emilio Paolo Visintin (iD https://orcid.org/0000-0003-2250-3533

Jacques Berent (iD https://orcid.org/0000-0003-1237-2664

Eva G. T. Green (iD https://orcid.org/0000-0003-1516-0157

Juan Manuel Falomir-Pichastor (iD https://orcid. org/0000-0002-2177-8511

\section{REFERENCES}

Aiken, L. S., West, S. G., \& Reno, R. R. (1991). Multiple regression: Testing and interpreting interactions. Newbury Park, CA: Sage.

Allport, G. W. (1954). The nature of prejudice. New York, NY: Addison-Wesley.

Asbrock, F., Christ, O., Duckitt, J., \& Sibley, C. G. (2012). Differential effects of intergroup contact for authoritarians and social dominators: A dual process model perspective. Personality and Social Psychology Bulletin, 38, 477-490. https://doi.org/10.1177/0146167211429747 
Asbrock, F., Gutenbrunner, L., \& Wagner, U. (2013). Unwilling, but not unaffected-Imagined contact effects for authoritarians and social dominators. European Journal of Social Psychology, 43, 404-412. https://doi.org/10.1002/ejsp.1956

Bosetti, V., Cattaneo, C., \& Verdolini, E. (2015). Migration of skilled workers and innovation: A European perspective. Journal of International Economics, 96, 311-322. https://doi.org/10.1016/j. jinteco.2015.04.002

Breugelmans, S. M., \& van de Vijver, F. J. R. (2004). Antecedents and components of majority attitudes toward multiculturalism in the Netherlands. Applied Psychology: An International Review, 53, 400422. https://doi.org/10.1111/j.1464-0597.2004.00177.x

Crisp, R. J., \& Turner, R. N. (2012). The imagined contact hypothesis. Advances in Experimental Social Psychology, 46, 125-182. https://doi. org/10.1016/B978-0-12-394281-4.00003-9

Dermody, N., Jones, M. K., \& Cumming, S. R. (2013). The failure of imagined contact in reducing explicit and implicit out-group prejudice toward male homosexuals. Current Psychology, 32, 261-274. https:// doi.org/10.1007/s12144-013-9182-5

Dhont, K., \& Van Hiel, A. (2009). We must not be enemies: Interracial contact and the reduction of prejudice among authoritarians. Personality and Individual Differences, 46, 172-177. https://doi.org/10.1016/j. paid.2008.09.022

Dhont, K., Van Hiel, A., \& Hewstone, M. (2014). Changing the ideological roots of prejudice: Longitudinal effects of ethnic intergroup contact on social dominance orientation. Group Processes \& Intergroup Relations, 17, 27-44. https://doi.org/10.1177/1368430213497064

Dixon, J., Durrheim, K., \& Tredoux, C. (2007). Intergroup contact and attitudes toward the principle and practice of racial equality. Psychological Science, 18, 867-872. https://doi.org/10.1111/j.1467-9280.2007.01993.x

Duckitt, J., \& Sibley, C. G. (2009). A dual-process motivational model of ideology, politics, and prejudice. Psychological Inquiry, 20, 98-109. https://doi.org/10.1080/10478400903028540

Frederic, N. S., \& Falomir-Pichastor, J. M. (2018). Heterogeneity of ingroup identity and anti-immigrant prejudice: The moderating role of RWA and outgroup homogeneity. International Review of Social Psychology, 31, 13. https://doi.org/10.5334/irsp.152

Green, E. G., Fasel, N., \& Sarrasin, O. (2010). The more the merrier? The effects of type of cultural diversity on exclusionary immigration attitudes in Switzerland. International Journal of Conflict and Violence, 4, 177-190. https://doi.org/10.4119/UNIBI/ijcv.79

Green, E. G. T., \& Staerkle, C. (2013). Migration and multiculturalism. In L. Huddy, D. O. Sears, \& J. Levy (Eds.), Oxford handbook of political psychology (pp. 852-889). Oxford, UK: Oxford University Press.

Guimond, S., de la Sablonnière, R., \& Nugier, A. (2014). Living in a multicultural world: Intergroup ideologies and the societal context of intergroup relations. European Review of Social Psychology, 25, 142-188. https://doi.org/10.1080/10463283.2014.957578

Hodson, G. (2008). Interracial prison contact: The pros for (socially dominant) cons. British Journal of Social Psychology, 47, 325-351. https:// doi.org/10.1348/014466607X231109

Islam, M. R., \& Hewstone, M. (1993). Dimensions of contact as predictors of intergroup anxiety, perceived out-group variability, and out-group attitude: An integrative model. Personality and Social Psychology Bulletin, 19, 700-710. https://doi.org/10.1177/0146167293196005

Jetten, J., \& Spears, R. (2003). The divisive potential of differences and similarities: The role of intergroup distinctiveness in intergroup differentiation. European Review of Social Psychology, 14, 203-241. https://doi.org/10.1080/10463280340000063

Klein, R. A., Ratliff, K. A., Vianello, M., Adams, R. B., Bahník, Š., Bernstein, M. J., ... Nosek, B. A. (2014). Investigating variation in replicability: A "many labs" replication project. Social Psychology, 45, 142-152. https://doi.org/10.1027/1864-9335/a000178

Kteily, N. S., Hodson, G., Dhont, K., \& Ho, A. K. (2019). Predisposed to prejudice but responsive to intergroup contact? Testing the unique benefits of intergroup contact across different types of individual differences. Group Processes \& Intergroup Relations, 22, 3-25. https:// doi.org/10.1177/1368430217716750

Levin, S., Matthews, M., Guimond, S., Sidanius, J., Pratto, F., Kteily, N., ... Dover, T. (2012). Assimilation, multiculturalism, and colorblindness: Mediated and moderated relationships between social dominance orientation and prejudice. Journal of Experimental Social Psychology, 48, 207-212. https://doi.org/10.1016/j.jesp.2011.06.019

Mahfud, Y., Badea, C., Guimond, S., Anier, N., \& Ernst-Vintila, A. (2016). Distance culturelle, perception du multiculturalisme et préjugés envers les immigrés en France. L'Année Psychologique, 116, 203-225. https://doi.org/10.4074/S000350331600035X

Mazzoleni, O., \& Pilotti, A. (2015). The outcry of the periphery? An analysis of Ticino's no to immigration. Swiss Political Science Review, 21, 63-75. https://doi.org/10.1111/spsr.12147

Miles, E., \& Crisp, R. J. (2014). A meta-analytic test of the imagined contact hypothesis. Group Processes \& Intergroup Relations, 17, 3-26. https://doi.org/10.1177/1368430213510573

Pettigrew, T. F., \& Tropp, L. R. (2006). A meta-analytic test of intergroup contact theory. Journal of Personality and Social Psychology, 90, 751783. https://doi.org/10.1037/0022-3514.90.5.751

Pettigrew, T. F., \& Tropp, L. R. (2008). How does intergroup contact reduce prejudice? Meta-analytic tests of three mediators. European Journal of Social Psychology, 38, 922-934. https://doi.org/10.1002/ ejsp.504

Pratto, F., Çidam, A., Stewart, A. L., Zeineddine, F. B., Aranda, M., Aiello, A., ... Henkel, K. E. (2013). Social dominance in context and in individuals: Contextual moderation of robust effects of social dominance orientation in 15 languages and 20 countries. Social Psychological and Personality Science, 4, 587-599. https://doi.org/10.1177/1948550612473663

Pratto, F., Sidanius, J., \& Levin, S. (2006). Social dominance theory and the dynamics of intergroup relations: Taking stock and looking forward. European Review of Social Psychology, 17, 271-320. https://doi. org/10.1080/10463280601055772

Rosenthal, R., \& Rosnow, R. L. (1985). Contrast analysis: Focused comparisons in the analysis of variance. New York, NY: Cambridge University Press.

Sarrasin, O., Green, E. G., Bolzman, C., Visintin, E. P., \& Politi, E. (2018). Competition-and identity-based roots of anti-immigration prejudice among individuals with and without an immigrant background. International Review of Social Psychology, 31, 12. https://doi.org/10.5334/irsp.155

Schmid, K., Hewstone, M., Küpper, B., Zick, A., \& Wagner, U. (2012). Secondary transfer effects of intergroup contact: A cross-national comparison in Europe. Social Psychology Quarterly, 75, 28-51. https:// doi.org/10.1177/0190272511430235

Sidanius, J., \& Pratto, F. (1999). Social dominance: An intergroup theory of social hierarchy and oppression. New York, NY: Cambridge University Press.

Snellman, A., \& Ekehammar, B. (2005). Ethnic hierarchies, ethnic prejudice, and social dominance orientation. Journal of Community \& Applied Social Psychology, 15, 83-94. https://doi.org/10.1002/casp.812

Swiss Federal Statistical Office. (2017). Rapport statistique sur l'intégration de la population issue de l'immigration [Statistical report on the integration of the population with an immigrant background]. Neuchâtel, Switzerland: Author.

Turner, R. N., Crisp, R. J., \& Lambert, E. (2007). Imagining intergroup contact can improve intergroup attitudes. Group Processes \& Intergroup Relations, 10,427-441. https://doi.org/10.1177/1368430207081533

Verkuyten, M. (2006). Multicultural recognition and ethnic minority rights: A social identity perspective. European Review of Social Psychology, 17, 148-184. https://doi.org/10.1080/10463280600937418

Verkuyten, M., Thijs, J., \& Bekhuis, H. (2010). Intergroup contact and ingroup reappraisal: Examining the deprovincialization thesis. Social Psychology Quarterly, 73, 398-416. https://doi. org/10.1177/0190272510389015 
West, K., Hotchin, V., \& Wood, C. (2017). Imagined contact can be more effective for participants with stronger initial prejudices. Journal of Applied Social Psychology, 47, 282-292. https://doi.org/10.1111/ jasp.12437

\section{SUPPORTING INFORMATION}

Additional supporting information may be found online in the Supporting Information section at the end of the article.
How to cite this article: Visintin EP, Berent J, Green EGT,

Falomir-Pichastor JM. The interplay between social dominance orientation and intergroup contact in explaining support for multiculturalism. J Appl Soc Psychol. 2019;00:1-9. https://doi.org/10.1111/jasp.12587 